\title{
The Impact of Innovative Technology on the Quality Assurance at Higher Education Institutions in Developing Countries: A Case Study of Jordan
}

\author{
Nidal Al-Ramahi and Mahmoud Odeh
}

\begin{abstract}
Quality assurance consider as one of the most important concerns in higher education institutions, which may influence the overall rank of universities. Innovation technology may play an important role in improving such quality of higher education institutions. Innovation technology provides several benefits, which are seen immediately, for instant, allowing students to share information easily and to discover new experiences within the education system. This study aims to find out the key factors of innovative technology affecting the quality assurance at higher education institutions in Jordan. By adopting the diffusion of innovation theory, this study sheds light on several factors that extended from this theory. Fieldwork including five universities in Jordan was conducted to specify the actual technological factors that may influence quality assurance at higher education institutions. An interpretive paradigm using triangulation methods was applied to collect data, conducting sixteen semi-structured interviews with major stakeholders in Jordanian universities, including professors, university vice-chancellors, IT managers, heads of departments, and deans of schools. The researchers also held two focus groups and distributed 232 surveys to Jordanian students.
\end{abstract}

Index Terms-Innovative technology, quality assurance, higher education, developing countries, the Kingdom of Jordan.

\section{INTRODUCTION}

Research into the ways that information and communication technology (ICT) can be used to support educational institutions is not a new topic. Limited research, however, has been conducted regarding the use of ICT by higher education (HE) institutions in developing countries, especially in Jordanian universities. This research is intended to assist Jordanian higher education institutions (JHEIs) in adopting innovative technology to improve the education quality, by defining the main factors. According to [1], many indicators demonstrate the inefficiency of HE in Jordan; for example, the high unemployment level of graduates and the low rate of return to HE. One of the key factors contributing to these shortcomings is the failure to adopt the latest information technologies in HE programs.

Several benefits could be gained through the adoption of innovative technology at higher education such as Providing new creative and different methods of teaching and learning as alternatives to traditional classroom methods. Besides, it can provide more flexibility in terms of reaching documents from any place and at any time. Furthermore, it can be

Manuscript received March 11, 2020; revised June 2, 2020.

Nidal Al-Ramahi and Mahmoud Odeh are with Zarqa University, Jordan (e-mail: ramahinedal@zu.edu.jo,Modeh@Zu.edu.jo). expanding collaboration and knowledge sharing among students beyond the classroom [2].

However, it has been observed that Jordanian universities are still using traditional methods in teaching and learning. The lack of usage of technological innovation could be one of the reasons holding back JHEIs. This needs further investigation into the factors influencing the adoption of innovative technology in JHEIs and suggests a solution to increase such adoption. Moreover, the term quality assurance also introduces several challenges such as the definition of quality itself, the quality measurement, as well as the direct and indirect influence of several factors such as innovation technology.

The researchers were already aware of the current limitations and gaps in using innovative technology and its influence on the quality of higher education, which defined the problem that led to the research questions. The limitations of using innovative technology in JHEI suggest research into several questions, as follows:

1. How can Jordanian universities benefit from the adoption of innovative technology to improve education quality?

2. What are the main factors that influencing the adoption of innovative technology in JHEIs?

3. What is the effect of such factors on the quality assurance in JHEIs?

\section{QUALITY IN THE HIGHER EDUCATION CONTEXT}

In an attempt to define what the authors understand as quality within the educational context this section revisits the concept of quality adopted from Harvey and Knight [3] as follows:

The excellence, standards, perfection, conformance to requirements, fitness for purposes and value for money of the educational technology services level and higher education institutions outcomes.

This section emphasizes the factors that can be derived from this definition as illustrated in Table I. This research will study such factors in relation to innovative technology within JHEIs. Table I indicates five factors that define quality. In the context of innovative technology, the first refers to the excellence of technology services, and to achieving the minimum expectations of such services to improve the HE quality. The second refers to the perfection of technology and the ability to avoid any anticipated limitations, such as service downtime, and delayed response time. The third factor is value for money, comparing it with the value of the benefits of services provided to the students and staff in improving the quality of teaching and learning. Fitness for 
purpose compares the innovative technology services with their suitability for the university's purposes. The final factor describes the quality of the HE institution's outcomes, and its role in fulfilling labor market requirements.

TABLE I: THE INDICATOR OF QUALITY

\begin{tabular}{|c|c|c|}
\hline Quality & Definition & Key concepts \\
\hline Excellence & $\begin{array}{l}\text { Usually operationalized as } \\
\text { exceptionally high standards of } \\
\text { achievement [4]. }\end{array}$ & $\begin{array}{l}\text { Exclusivity, } \\
\text { exceeding high } \\
\text { standards or } \\
\text { fulfilling minimum } \\
\text { absolute standards }\end{array}$ \\
\hline Perfection & $\begin{array}{l}\text { Focuses on processes and sets } \\
\text { specifications that it aims to } \\
\text { meet [5]. }\end{array}$ & $\begin{array}{l}\text { Zero defects via a } \\
\text { quality culture } \\
\text { emphasizing 'right } \\
\text { first time. }\end{array}$ \\
\hline Value for & $\begin{array}{l}\text { Assesses quality in terms of } \\
\text { return on investment or }\end{array}$ & $\begin{array}{l}\text { Accountability via } \\
\text { performance }\end{array}$ \\
\hline Money & expenditure [3]. & $\begin{array}{l}\text { indicators or } \\
\text { customer charters. }\end{array}$ \\
\hline $\begin{array}{l}\text { Fitness for } \\
\text { Purpose }\end{array}$ & $\begin{array}{l}\text { Judges quality in terms of the } \\
\text { extent to which products or } \\
\text { services meet stated purposes } \\
\text { [6]. }\end{array}$ & $\begin{array}{l}\text { Meeting customer } \\
\text { specifications or } \\
\text { fulfilling the } \\
\text { institution's } \\
\text { mission. }\end{array}$ \\
\hline $\begin{array}{l}\text { Higher } \\
\text { education } \\
\text { institution } \\
\text { outcomes }\end{array}$ & $\begin{array}{l}\text { The gap between the } \\
\text { universities' outcomes and the } \\
\text { labor market, based on the } \\
\text { learning and teaching process } \\
\text { and outcomes [7]. }\end{array}$ & $\begin{array}{l}\text { Enhancing or } \\
\text { empowering the } \\
\text { student's level } \\
\text { through adopting } \\
\text { innovative } \\
\text { technology. }\end{array}$ \\
\hline
\end{tabular}

\section{THE ROLE OF INFORMATION TECHNOLOGY IN HIGHER EDUCATION INSTITUTIONS: A SUMMARY OF HISTORICAL EVOLUTION}

The role of information technology in improving education quality is not a new phenomenon. In 1946, the University of Pennsylvania developed the first electronic computer in the USA. The Electronic Numerical Integrator and Computer (ENIC) was developed to speed up complex calculations, allow multiple users to work at the same time, and finally to receive a printed paper with results after inputting data into the program [8]. ENIC made the whole process, which included feeding the program using punch cards, waiting for the completion of the process, and receiving results, very short compared with the more labor-intensive manual process.

From the 1950s until the 1960s, mainframe computers were available only in major research universities, with the aim of improving the field of computer science [8]. However, the use of mainframe computers was limited, due to their high cost, a large amount of space needed to house them, and the limited number of faculty and students who knew how to use this technology.

The role of information technology in improving education quality is not a new phenomenon. In 1946, the University of Pennsylvania developed the first electronic computer in the USA. The Electronic Numerical Integrator and Computer (ENIC) was developed to speed up complex calculations, allow multiple users to work at the same time, and finally to receive a printed paper with results after inputting data into the program [8]. ENIC made the whole process, which included feeding the program using punch cards, waiting for the completion of the process, and receiving results, very short compared with the more labor-intensive manual process.

From the 1950s until the 1960s, mainframe computers were available only in major research universities, with the aim of improving the field of computer science [8]. However, the use of mainframe computers was limited, due to their high cost, a large amount of space needed to house them, and the limited number of faculty and students who knew how to use this technology.

The evolution of computer networking was another major change in information technology. In the 1970s, Carnegie Mellon University and Massachusetts Institution of Technology (MIT) adopted two network projects, Andrew and Athena, whose aim was to create a new network that connected students, faculties, and staff. The first version was the distributed computing model, which connected different workstations and servers including different brands software and operating systems, such as IBM, and UNIX.

Although the distributed computing model was very expensive, most universities adopted it in the 1980s, as it created new concepts in sharing and communication, allowing users to communicate via an electronic mail system, and to share research documents in the university library and access information resources in an effective way.

The biggest leap in computing technology within the education sector was in 1981, when IBM introduced the personal computer, followed in 1984 by the Apple Macintosh Personal Computer. Personal computers allowed users to simplify the complex computing process with the same performance offered by mainframe computers, but at a lower cost. The new software was introduced, such as word processing, spreadsheet and graphical interface programs, which constituted the major change for the education sector at that time [8].

According to Westera [9], information technology played a notable role in universities and schools around the world, which in turn were forerunners in improving educational quality through their extensive use of information technology [10]. In the same context, Ensminger and Lewis [11] argue that technology changed the face of HE, allowing students to access almost unlimited resources, and motivating universities to provide a creative learning environment. Moreover, technology improves students' research skills, and creates professional learners.

Forest and Kinser [8] claim that policy makers considered technology to be a solution to many HE challenges, such as improving quality, decreasing costs, increasing creativity and productivity, and improving research cooperation. In the $21^{\text {st }}$ century, the evolution of smartphones, cell phones, tablets, online information communications, and new tools for education have increased research sharing and access to resources among students, researchers and learners [12].

Several recent studies have demonstrated that students prefer learning methods supported by technology, rather than old learning methods [13]-[15]. Accordingly, it is difficult to ignore the evolution of technology in education, even in developing countries. HE institutions must be aware of the 
best ways forward for education technology integration and communication. Therefore, the process of adopting the right technology in the best way is one of the most important methods for improving the quality of HE [16]. For this reason, developing nations seeking better HE quality outcomes and improved economic growth should be more familiar with education technology.

\section{The Role Of InNOVAtive TeChNOlOGY IN HigheR EDUCATION INSTITUTIONS IN DEVELOPING COUNTRIES}

This section describes the use of Innovative technology in developing countries and the importance of technology in higher education institutions. Developing countries have usually been left behind in the adoption and implementation of innovative technology [17]. Under-utilisation of such technology has negatively affected knowledge sharing and the quality of higher education.

According to Stein et al. [18], innovative technology can increase efficiency in education, improve its quality, and reduce overall information and communication technology costs. This has been observed in several educational institutions in East Africa (e.g. the University of Nairobi, the Kigali Institute for Education, and the Kenyan Methodist University), which collaborated with Google to gain significant benefits from Google Cloud applications for both students and lecturers [19].

In Ethiopia, Microsoft has supported education institutions by rolling out 250,000 laptops to lecturers. All of these laptops run Windows Azure, an operating system on cloud technology [20]. Lecturers can use Windows Azure to upload and download curricula, and securely transfer students' records to the education system. These releases education institutions in Ethiopia from investing heavily in data centers or in the expensive hardware and software necessary for connecting such a large amount of transactions.

In a large longitudinal study [21] investigated the impact of innovative technology on the economy of 11 countries in the Middle East (Jordan, Oman, Yemen, Saudi Arabia, Qatar, Syria, the United Arab Emirates, Bahrain, Iran, Kuwait, and Lebanon). The study concluded that there is a strong correlation between the quality of $\mathrm{HE}$ and the utilization of information and communication technology. It also showed that countries such as Jordan, Kuwait and Bahrain, which have flexibility in roles and policies, were able to achieve benefits from ICT such as improving social economy; other countries, such as Iran and Syria, were less advantaged by innovative technology because of government constraints and policies which prevented the growth of a technological infrastructure.

\section{DIFFUSION OF INNOVATION THEORY}

Everett Rogers was a Professor of Communication Studies who first expounded the diffusion of innovation (DOI) theory in his book Diffusion of Innovations in 1962. DOI is widely used in technology adoption studies, and by 2003 had reached its fifth edition. The main aim of the DOI theory is to help both organizations and individuals, whether in accepting or rejecting innovation [22]. Another aim is to provide clear estimates of how long it will take to adopt and accept innovative technology.

According to Rogers [23], diffusion is defined as "the process in which an innovation is communicated through certain channels over time among the members of a social system" p.12. This definition suggests four main elements in DOI theory: (1) the innovation, (2) communication channels, (3) time, and (4) the social system.

\section{A. DOI Theory's Main Element}

The innovation is defined as "an idea, practice, or object that is perceived as new by an individual or another unit of adoption" [24] p.62. The innovation does not need to be objectively new, and may vary from one individual or organization to another. If an idea appears new to an individual or organization, it is an innovation [24].

Communication channels refer to the process of creating and sharing information between individuals. As Rogers states: "the diffusion process is the information exchange through which one individual communicates a new idea to one or several others" [24] p.18.

Time: There are three main aspects of the element of time in DOI theory. First is the innovation-decision process, which has five stages, from the individual's first knowledge of the innovation, through to its adoption or rejection. Next, innovativeness refers to the earliness/lateness of a member's innovation adoption within the same system. Third comes the innovation rate, which is normally measured by the number of members who adopt the innovation in a particular period [24].

TABLE II: THE DIFFUSION OF INNOVATION STAGES

\begin{tabular}{ll}
\hline \hline Stage & Description \\
\hline \multirow{2}{*}{ Knowledge } & The first stage, when the individuals or \\
& decision unit know about the existence of the \\
& innovation and have the opportunity to \\
& understand how it functions.
\end{tabular}

Persuasion Consists of five characteristics: (1) relative advantage, (2) compatibility, (3) complexity, (4) trainability, (5) observability.

Decision In this stage, the individual or decision unit decides to adopt or reject the innovation. They may continue adopting the innovation or discontinue it after a period. The decision to reject the innovation may result in continuing the rejection as a permanent decision, or deciding to adopt the innovation later.

Implementation

At the implementation stage, the actual use of innovation in real life will take place.

Confirmation

This is the final stage, where the individual or decision-making unit evaluates the outcomes of innovation.

Social system: This is "a set of interrelated units that are engaged in joint problem-solving to accomplish a common goal" [24] p.23. These units could be individuals, groups, organizations, and/or subsystems. Sharing the same problem-solving process to reach the same targets can affect innovation diffusion, as can the structure and characteristics 
of the social system (i.e. social system units are not necessarily identical in their behavior).

\section{B. DOI Theory's Main Stages}

According to [24], five main stages affect an individual's decision to adopt or reject innovation within a social system, from knowledge to implementation. The innovation-decision process will vary from one individual to another. While some people need many years to adopt an innovation, others move rapidly from knowledge to implementation. Table II provides a brief description of the adopting/rejecting decision process stages. Whereas, Fig. 1 explain the innovation-decision process which started from the knowledge phase and end by confirmation decision of adoption of the innovation itself.

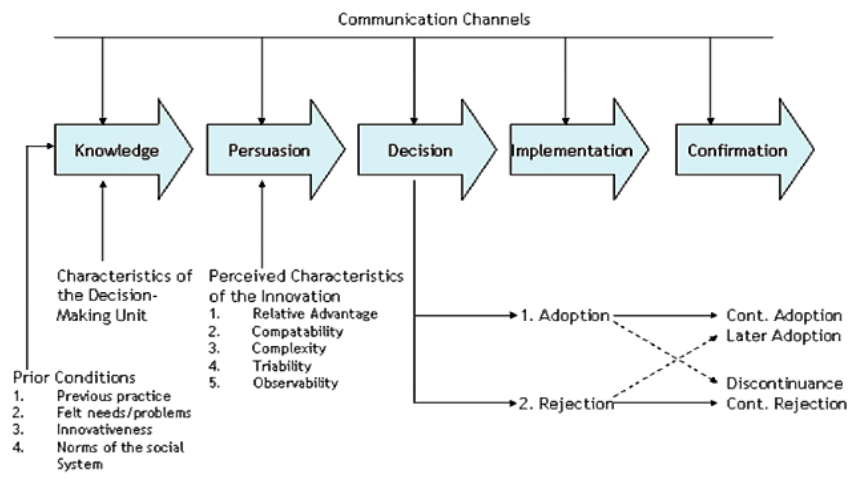

Fig. 1. Innovation-decisions process model [24].

\section{Figures Adopters Categories}

Innovativeness is "the degree to which an individual or another unit of adoption is relatively earlier in adopting innovative ideas than the other members of a system" [24] P.24. Rogers classified individuals or adoption makers according to five levels, relating to time, as seen in Fig. 2.

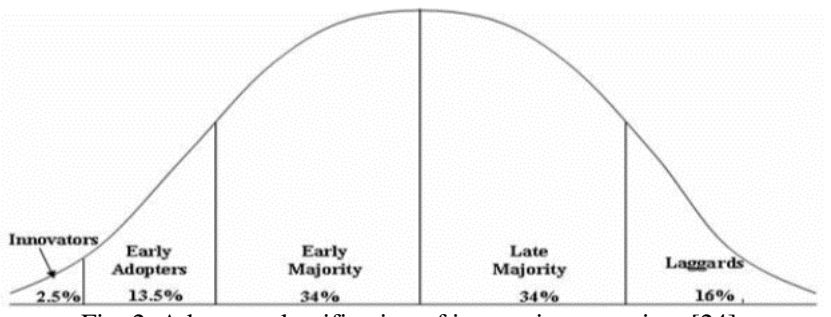

Fig. 2. Adopters classification of innovation over time [24]

\section{Research Methodology}

The data was collected from four HEIs in Jordan. As it was mentioned before, researchers conducting sixteen semi-structured interviews with major stakeholders in Jordanian universities, including professors in information technology, university vice-chancellors, IT managers, heads of departments, and deans of schools. The researchers also held two focus groups and distributed 232 surveys to Jordanian students.

The data was analyzed using NVivo software, and based on the three-step process recommended by Miles and Huberman [25]: data condensation, data display and drawing/verifying conclusions. Microsoft Excel was used to present information relating to frequencies or statistics (e.g. In the form of tables, pie charts, bar charts, and column charts).

\section{MAIN RESULTS}

As this study adopted a qualitative methodology using a triangulation of data to answer the research questions and address the research problem. Bell [26] argued that research methods have to be effective to solve the research problem. Tellis [27] emphasized the adoption of the triangulation methodology to enhance the understanding of the system under examination. Yin [28] focused on triangulation to meet the ethical requirement of authenticating the validity of the research. Adams et al. [29] argued that triangulation can be achieved by collecting data from multiple sources. Accordingly, this study found that there are several factors that may influence the quality of higher education in the light of technological factors as follows: Perfection, value for money, Fitness for Purpose, and higher education institution outcomes. Such factors have been connected directly with innovative technology to find out the influence of them on the quality of higher education.

\section{A. The Perfection of Innovative Technology Services}

The perfection of innovative technology services refers to the ability to achieve Zero defects via a quality culture emphasizing 'right first time'. However, it could be argued from the finding of this research that zero defect is almost impossible, especially in the long-term period. This means that HEIs could be seeking perfection as much as possible with the vision of perfection despite some rare errors that could exist. This argument agrees with one of the interviewees who working as a professor in information systems stated that:

Perfection in information technology to improve the quality of higher education is a dream that we hope to make it true. Computer hardware and software have several failures during the academic semester. However, if we compare the failure time with the overall time it could be said that we are fine and very close to perfection next academic years.

Findings from the survey showed that the majority of participants believed that the perfection of technological services has a direct influence on the quality of higher education. As can be seen from Fig. 3, 77\% of participants argued that there is a positive influence of the perfection on quality of higher education. Whereas $19 \%$ of participants cannot see any influence between perfection and quality and $4 \%$ did not know.

\section{Would the perfection of the innovative technology positively influence the quality of higher education?}

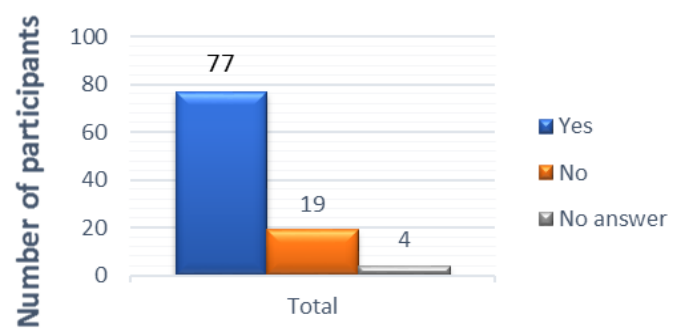

Fig. 3. Perfection of the innovation technology impact on the quality of higher education. 


\section{B. Value for Money Spent on Innovation Technology and Quality of Higher Education}

This factor refers to the return on investment in innovative technology, which can be evaluated based on the improvement of the quality of higher education. It is interesting to state that several interviewees argued that innovative technology is an expensive investment and the influence on quality comparing with such investment cannot be seen in the short term. As one of the participants who work as a dean of information technology school stated:

The startup cost of innovative technology is usually very expensive and it is very difficult to see the value of money spent on technology directly. In my opinion, we need at least 5 to 10 years to see the value of investing in technology and its effects on the quality of higher education and students' skills.

According to Fig. 4, finding from the survey shows that $55 \%$ of participants believed that it is worth to invest in innovative technology to improve that quality of higher education, $36 \%$ believed that there are no benefits through spending on innovative technology to improve the higher education quality, and 9\% did not know.

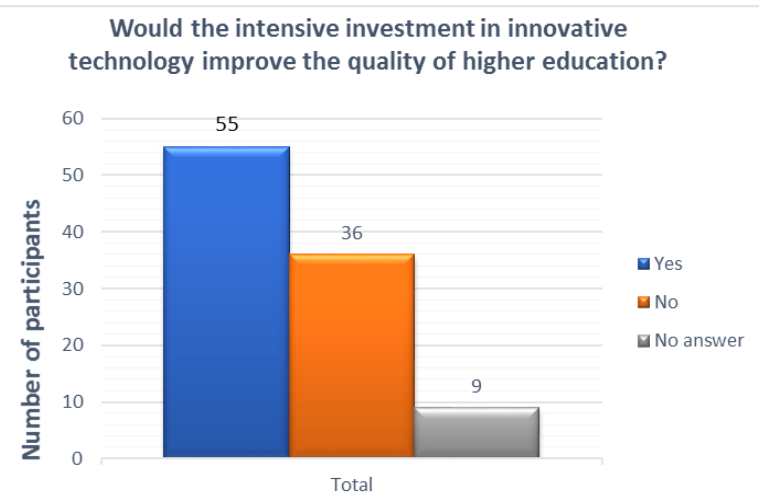

Fig. 4. The impact of the value of money spent on innovation technology on the quality of higher education

\section{Fitness for Purpose}

Fitness for purposes refers to selecting a suitable innovative technology, which meets the higher education institution specifications or fulfilling the requirements. The findings from this study show that the selection process of specific technology based on the university requirement is an essential step as there is extensive technology available. The biggest challenge is to know how to select a suitable technology to achieve fitness for purposes factor. One of the participants who work in a private university in Jordan as a deputy vice-chancellor said:

The technology itself is available and it is very easy to adopt it. The most important thing for adopting innovative technology is what and why we adopt a specific innovative technology. Simply our main goal is to improve the quality of higher education. Therefore, any selection should be based on improving quality. We have some good and bad experience in this field. I believe that the high cost of any software or hardware does not necessarily mean that it could serve our goal. In some cases, a free resource could be much better for our goal of improving the high-quality education level.

On the other hand, Fig. 5 shows that the successful selection of innovation technology play a major role in improving the quality of higher education. $56 \%$ of participants thought that fitness for purpose has a direct influence on the quality of higher education. Whereas $26 \%$ cannot see any relation between fitness for purpose and quality of higher education, and $18 \%$ did not know.

\section{Would selecting a suitable innovative technology improve the quality of higher education?}

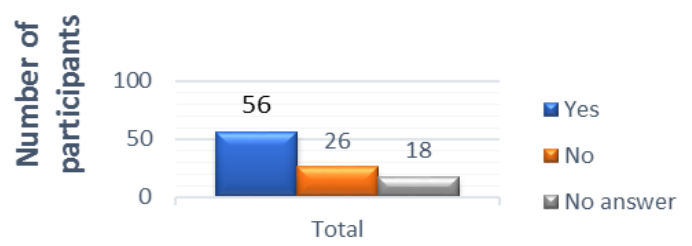

Fig. 5. The impact of selecting suitable innovative technology on the quality of higher education.

\section{Higher Education Institution Outcomes}

HEIs outcomes is another important factor, which refers to the quality of outcomes such as students, publications, reports, and any other outcomes from universities. However, it is very difficult to measure the university outcomes because there are several sub-factors inside this factor. For instance, the employment percentage for graduate students could be an important indicator as well as the feedback from employers about the quality level of graduate students. Another major outcome could be the research papers' quantity and quality and its effect globally. A dean of research school at one of the private universities participated in this study said:

Outcomes mean results and this is the most important factor in the quality of higher education. Successful means excellent outcomes and failure mean bad outcomes. The question could be what is excellent and poor and how can we measure them. There are several measurement tools and approaches that can be used such as universities ranking. For instance, $Q S$ world ranking and web metrics universities ranking may provide a good indicator for the quality of higher education institutions.

Findings from the survey show that the majority of participants believed that higher education institution outcomes are one of the most important factors that strongly influence the quality of higher education institutions.

\section{Would outcomes of higher education institutions impact the quality of higher education?}

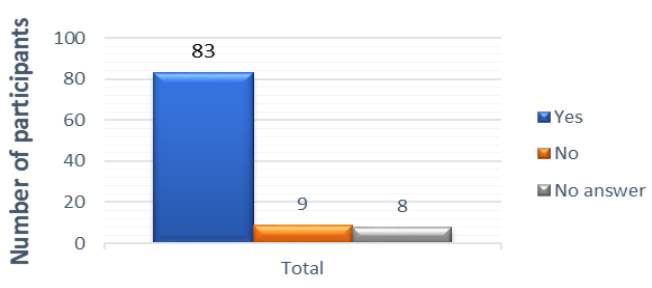

Fig. 6. The impact of higher education institutions outcomes on the quality of higher education.

As can be seen from Fig. 6, 83\% of participants believed that HEIs outcomes have a great impact on the quality of higher education. Whereas $9 \%$ believed that there is no 
impact for such factor on the HEIs quality, and $8 \%$ did not know.

\section{CONCLUSION}

This paper investigates the technological factors that influence the quality of higher education institutions in Jordan. Semi-structured interviews were conducted with professors, IT managers, and lecturers. Besides, 232 surveys have been successfully distributed and analyzed. The findings suggest that the adoption of innovative technology has a positive influence on the quality of HEIs in Jordan. Several factors have been investigated such as perfection, value for money, Fitness for Purpose, and higher education institution outcomes. Further research on the process of adopting innovative technology still required, especially in developing countries. Further studies in this domain may help academic institutions to improve the quality of higher education.

\section{CONFLICT OF INTEREST}

The authors declare no conflict of interest

\section{AUTHOR CONTRIBUTIONS}

Nidal designed the study, created the main outlines for the whole research, and suggest the timeline, which required 10 months for the whole process. Mahmoud collected the data and Nidal and Mahmoud analyzed worked on the data analysis process. Mahmoud wrote the results and finally Nidal review all the paper, add comments, and final corrections. Both authors had approved the final version.

\section{ACKNOWLEDGMENT}

This research is funded by the Deanship of Research in Zarqa University, Jordan.

\section{REFERENCES}

[1] S. Al-Jaghoub, H. Al-Yaseen, M. Hourani, and R. El-Haddadeh, "E-learning adoption in higher education in Jordan: Vision, reality and change," in Proc. European and Mediterranean Conference on Information Systems, 2009.

[2] S. Tout, W. Sverdlik, and G. Lawver, "Cloud computing and its security in higher education," in Proc. ISECON, vol. 2314, 2009.

[3] L. Harvey and P. T. Knight, Transforming Higher Education, 1996.

[4] L. Harvey and B. Stensaker, "Quality culture: Understandings, boundaries and linkages," European Journal of Education, vol. 43, no. 4, pp. 427-442, 2008

[5] L. Harvey, "Epistemology of quality," Perspectives in Education, vol. 25 , no. 3 , pp. $1-13,2007$.

[6] L. Harvey and D. Green, "Defining quality," Assessment \& Evaluation in Higher Education, vol. 18, no. 1, pp. 9-34, 1993.

[7] L. Harvey and L. Purser, "Understanding quality, Section B 4.1-1 'Introducing Bologna objectives and tools," EUA Bologna Handbook: Making Bologna Work, 2006.

[8] J. J. Forest and K. Kinser, Higher Education in the United States: AL. Abc-clio, 20021.

[9] W. Westera, "On strategies of educational innovation: Between substitution and transformation," Higher Education, vol. 47, no. 4, pp. 501-517, 2004

[10] C. Chiu and C. F. Moss, "The role of the external ear in vertical sound localization in the free flying bat, Eptesicus fuscus," J. Acoust. Soc. Am., vol. 121, no. 4, pp. 2227-2235, 2007.

[11] Ensminger and D. Lewis, "Technology in higher education: Understanding student issues," in Technology Integration in Higher Education: Social and Organizational Aspects: Social and Organizational Aspects, D. W. Surry, Ed. IGI Global, 2010.
[12] K. Parker, A. Lenhart, and K. Moore, "The digital revolution and higher education: College presidents, public differ on value of online learning," Pew Internet \& American Life Project, 2011.

[13] J. Milliken and L. P. Barnes, "Teaching and technology in higher education: Student perceptions and personal reflections," Comput. Educ., vol. 39, no. 3, pp. 223-235, 2002.

[14] R. M. Tamim, G. Lowerison, R. F. Schmid, R. M. Bernard, P. C. Abrami, and C. Dehler, "Assessing computer use and perceived course effectiveness in post-secondary education in an American/Canadian context," Journal of Educational Computing Research, vol. 39, no. 3 pp. 221-234, 2008

[15] J. Webster and P. Hackley, "Teaching effectiveness in technology-mediated distance learning," Academy of Management Journal, vol. 40, no. 6, pp. 1282-1309, 1997 .

[16] M. M. Odeh, "A proposed theoretical solution for transferring from physical to virtual machines based on cloud computing," in Proc. 2019 5th International Conference on Information Management (ICIM), 2019, pp. 221-226.

[17] H. M. Sabi, F. E. Uzoka, K. Langmia, and F. N. Njeh, "Conceptualizing a model for adoption of cloud computing in education," Int. J. Inf. Manage., vol. 36, no. 2, pp. 183-191, 2016.

[18] S. Stein, J. Ware, J. Laboy, and H. E. Schaffer, "Improving K-12 pedagogy via a cloud designed for education," Int. J. Inf. Manage., vol 33, no. 1, pp. 235-241, 2013.

[19] N. Sultan, "Cloud computing: A democratizing force?" Int. J. Inf. Manage., vol. 33, no. 5, pp. 810-815, 2013.

[20] N. Sultan, "Cloud computing for education: A new dawn?" Int. J. Inf. Manage., vol. 30, no. 2, pp. 109-116, 2010.

[21] F. Shirazi, R. Gholami, and D. A. Higón, "The impact of information and communication technology (ICT), education and regulation on economic freedom in Islamic Middle Eastern countries," Information \& Management, vol. 46, no. 8, pp. 426-433, 2009.

[22] M. H. Fagan, "Global information technology transfer: A framework for analysis," Journal of Global Information Technology Management, vol. 4, no. 3, pp. 5-26, 2001.

[23] E. M. Rogers, Diffusion of Innovations, Simon and Schuster, 2010.

[24] E. M. Rogers, Diffusion of Innovations, 5th ed. New York: Free Press, 2003.

[25] M. Miles, A. Huberman, and J. Saldaña, Qualitative Data Analysis. A Methods Sourcebook, 2014.

[26] J. Bell, Doing Your Research Project: A Guide for First-Time Researchers, UK: McGraw-Hill Education, 2014.

[27] W. M. Tellis, "Application of a case study methodology," The Qualitative Report, vol. 3, no. 3, pp. 1-19, 1997.

[28] Yin, "Case study research: Design and methods," Sage Publications, 2013.

[29] J. Adams, H. T. Khan, R. Raeside, and D. I. White, "Research methods for graduate business and social science students," SAGE Publications India, 2007.

Copyright (C) 2020 by the authors. This is an open access article distributed under the Creative Commons Attribution License which permits unrestricted use, distribution, and reproduction in any medium, provided the original work is properly cited (CC BY 4.0).

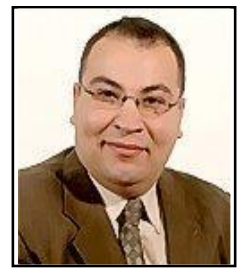

Nidal Alramahi is the vice president of Zarqa University for Academic and Quality Affairs and a professor in Accounting Information Systems.

He has developed himself in the academic career as a successful professor with more than 22 years of experience, to be involved and updated with the academic research work and maintain a link to the corporate world through the experience that he gained by being a consultant and a trainer. Maintaining links with the corporate world helps to minimize the gap between academic teaching and corporate reality and enables him to help students to be successful in their career life.

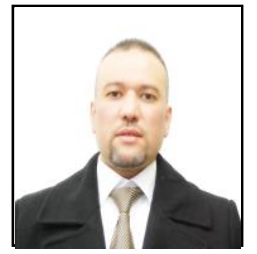

Mahmoud Odeh is a senior assistant professor in Zarqa University who finished his $\mathrm{PhD}$ from Coventry University, UK. Mahmoud hold more than 13 years' experience in both practical and academic field with 56 international certificates in servers, computer virtualization, smart machines simulation, and cloud computing. His current research is inspired by the rapid evolution of Cloud Computing technology, which mainly focus on the implementation of innovation technology. 